\title{
EXTENSÃO ACADÊMICA: UMA APOSTA PELA DEMOCRATIZAÇÃO DO CONHECIMENTO
}

\author{
Alcides Leão Santos Junior*
}

\begin{abstract}
Resumen
Estudió la extensión académica como uno de los elementos que fomenta el diálogo entre las universidades y la sociedad. La extensión académica está produciendo un conocimiento logrado de las experiencias en el que la toma de tema se convierte en el papel de productor y locutor de los conocimientos, y, cuando están construidos en conocimiento factual, otros nacen y son circulares y crea posibilidades para ser probados y han añadido nuevos valores a ellos. Por lo tanto, hablar de extensión académica como producir conocimiento requiere reflexionemos sobre la Universidad y la sociedad de la inter-relation a través de la educación y la praxis social con el eje de la autonomía del sujeto. Se trata de una investigación teórica sobre la base de estudios de Boaventura de Souza Santos y la investigación documental. Existe la posibilidad de que en la extensión de la producción académica del conocimiento es el resultado de las interacciones socio-culturales que muestran los procesos cognitivos válidos que se basan en una combinación de conocimientos de conocimiento/provisional pero no fragmentado o independiente descontextualizados así sujetos y capaz de inferir modificaciones en los espacios geo-social. Por lo tanto, cuando ella entendida como proceso formativo permite sujeto a la superación de una teoría de concreción y finitud humana de procesos históricos que se producen en una relación de diálogo que conduce a la autonomía.
\end{abstract}

\section{Palabras clave}

Extensión académica - Universidad - Universidad y la sociedad - Producción de conocimiento - Educación y formación.

\section{Resumo}

Estuda-se a extensão acadêmica como um dos elementos que fomenta o diálogo entre a Universidade e a sociedade. A extensão acadêmica é produtora de um

* Mestre em Ciências Sociais (UFRN). Pedadgo (UCSAL). Doutorando em Educação (UFBA) 
conhecimento concretizado a partir das experiências em que os sujeitos se revezam nos papéis de produtor e difusor de conhecimentos, e, quando são construídas numa relação dialógica, outros conhecimentos nascem e passam a circular e cria possibilidades de ser testado e de ter agregado a eles novos valores. Assim, discutir a extensão acadêmica como produtora de conhecimentos requer refletir sobre a interrelação Universidade e Sociedade via educação e práxis social tendo como eixo a autonomia dos sujeitos. Trata-se de uma pesquisa teórica com base nos estudos de Boaventura de Souza Santos e de pesquisa documental. Vislumbra-se que na extensão acadêmica a produção de conhecimentos é fruto de interações sócio-cultural que evidenciam processos cognitivos válidos que se apóiam numa conjunção de saberes/ conhecimentos provisórios, mas não fragmentados ou descontextualizados produzindo assim sujeitos autônomos e capazes de inferir modificações nos espaços geo-sociais. Assim, quando compreendida enquanto processo formativo ela permite aos sujeitos à superação de uma teoria de concretude e finitude dos processos históricos humanos que acontecem numa relação de diálogo que conduz a autonomia.

\title{
Palavras Chave
}

Extensão acadêmica - Universidade - Universidade e sociedade - Produção de conhecimento - Educação e formação.

\begin{abstract}
Studied academic extension as one of the elements that fosters dialogue between universities and society. The academic extension is producing a knowledge achieved from the experiences in which the subject take turns in the roles of producer and broadcaster of knowledge, and, when they are built into factual knowledge, others are born and are circular and creates possibilities to be tested and have added new values to them. So, discuss academic extension as producing knowledge requires ponder the inter-relation University and Society via education and social praxis with axis the autonomy of the subject. This is a theoretical research on the basis of studies of Boaventura de Souza Santos and documentary research. There is that in the extension academic production of knowledge is the result of socio-cultural interactions that show valid cognitive processes that rely on a combination of knowledge/provisional knowledge but not fragmented or stand-alone descontextualizados thereby subject and able to infer modifications in geo-social spaces. So, when she understood as formative process allows subject to overcoming a theory of concreteness and human finitude of historical processes that happen in a relationship of dialogue that leads to autonomy.
\end{abstract}

\section{Key words}

Academic extension - University - University and society - Knowledge production Education and training. 


\section{Introdução}

A atividade de extensão é o caminho básico para a Universidade descobrir o mundo e para o mundo descobrir a Universidade. (Buarque, 1994, p. 137):

Sabe-se que, no ambiente acadêmico abriga em seu espaço contradições e acontecimentos de uma ordem social, política e histórica na qual se entrecruzam indivíduos com diferentes modos de ser, de pensar, de agir e de compreender a si e ao mundo. Através dessa constatação objetivamos estudar a extensão universitária como um dos elementos que fomenta o diálogo entre esta secular instituição educativa (e formativa) - a Universidade - e a sociedade. Pois, como prega Buarque (1994, p. 137), na epigrafe acima, "a atividade de extensão é o caminho básico para a Universidade descobrir o mundo e para o mundo descobrir a Universidade".

É importante destacar que nossa preocupação com um dos tripés da universidade reside no fato de que a vemos como um espaço de aprendizagem cuja existência e concretude não se verificam nas experiências de avaliação institucional voltadas para a consolidação da reflexão-ação-reflexão dos acadêmicos fato confirmado através de documentos do Fórum de PróReitores de Extensão das Universidades Públicas Brasileira e de instrumentos norteadores para a avaliação das instituições de ensino superior no Brasil.

Diante deste argumento vale lembrar que o conceito de extensão universitária, no Brasil, sofre profunda alteração a partir do I Encontro de Pró-Reitores de Extensão das Universidades Públicas Brasileiras, realizado em novembro de 1987, na cidade de Brasília/DF, passa a definir a extensão universitária como um "[...] processo educativo, cultural e científico que articula o ensino e a pesquisa de forma indissociável e viabiliza a relação transformadora entre universidade e sociedade." (Nogueira, 2000, p. 11). Nessa conceituação, que merece cuidadosamente ser discutida, vislumbramos uma tentativa de aproximar a educação superior à sociedade via extensão universitária que procura manter na sua essência um dialogo [permanente] entre os envolvidos nas ações extensionistas.

Longe de imaginarmos a possibilidade de transformação histórico-social do país apenas na/pela educação nosso intuito é apostar numa ação extensionista capaz de favorecer essa discussão e quiçá proporcionar essa transformação. A saber, a gênese da extensão universitária no Brasil, para Paiva (1974), Sousa (2000), Jezine (2006), confunde-se com a do movimento estudantil tendo em vista que os estudantes sempre se envolviam como os as questões sociais e político da sua época. Historicamente, sabemos que, no Brasil Colônia os jovens lutavam pela abolição dos escravos e pela Proclamação da República; no Estado Novo (1937 - 1945) lutaram pela criação da União Nacional dos Estudantes (UNE) e contra os ideais do nazofascismo; no período da Ditadura 
Militar (1964 - 1985) a pelo combate ao analfabetismo e o regime autoritário e atualmente conta a implantação da política neoliberal que proporcionou a ausência de recursos para as universidades públicas. Esse cenário tem levado as universidades, hoje, à prestação de serviços, via extensão universitária, a fim de obterem recursos para se manterem. Sousa $(2000$, p. 13) salienta que a universidade incorporou:

[...] ao longo do tempo e em diferentes contextos, funções diversas. São atribuídas à universidade as funções de transmissão, de produção e de Extensão do sabe, sendo o ensino a função mais tradicional pois se consubstancia na transmissão de conhecimentos. A Universidade tem, ainda, a função de socializar o saber que produz e, desta forma, é também responsabilizada pela integração social dos indivíduos. Nesse ponto é que se podem encontrar os sinais da existência da Extensão Universitária, pois tanto a transmissão como a produção do saber serão sempre uma forma de prestação de serviços a alguém.

A extensão universitária não se constituiu a partir da universidade, mas a partir das demandas da sociedade. Ela visa uma busca do rompimento de uma postura hegemônica que é explicitada das diferenças de saberes e cultura.

Vislumbramos a extensão universitária enquanto espaço aglutinador de ideologias capaz de contribuir para a transformação da realidade social, mas é imprescindível pensa-la como o único instrumento mediador entre universidade e sociedade.

Ao analisar as concepções e práticas extensionistas Jezine (2006) aponta três modelos: o assistencialista que advém das práticas de assessorias cuja instrumentalização técnica centra-se nas áreas de educação, agricultura e saúde em que a universidade deveria levar seus conhecimentos às comunidades desprovidas de saberes e oferecer serviços que contribuam para o desenvolvimento social do país; o mercantilista que formou se ao longo das mudanças ocorridas na estrutura econômica e política do Estado e da sociedade sob a perspectiva de "venda de serviços", representando as iniciativas de privatização; e o acadêmico que resulta da organização e luta pelo reconhecimento da dimensão filosófico-científica da extensão, a universidade é compreendida como um elo integrador com a sociedade e o que tem a extensão, o ensino e a pesquisa como componentes inerentes ao processo de mudança social e de difusão cultural; busca-se o equilíbrio entre os saberes populares e os saberes científicos numa perspectiva dialógica.

É sabido que o processo de construção do conhecimento acadêmico sofre, inegavelmente, efeitos de relação de poder. O conhecimento científico não é um saber obrigatoriamente verdadeiro, mas tem-se a pretensão de estabelecer uma verdade por isso precisa ser legitimado pelas instituições. Nessa visão o conhecimento é eleito para produzir (in)consciências. 
Observamos na legislação brasileira (Lei 9394/96 e nos documentos de extensão universitária) a existência de um hiato entre os conhecimentos sociais e os conhecimentos científicos. Para tanto sustentamos a necessidade destes começarem a dialogar (ou re-ligar). Subverter a lógica (a da separação), na contemporaneidade, que se mostra favorável do desenvolvimento de uma mentalidade comprometida com o progresso e fiel à aposta de uma "monocultura da mente", (Shiva, 2003, é tornar-se um marginal. Contudo, há ainda, neste universo "pó de estrelas que sonham" e acreditam e sonham com uma reforma do pensamento. Afinal, "tudo que era sólido se desmancha no ar" (Marx; Engels, 2004) e no campo do fazer acadêmico que vimos eleição de conhecimentos necessários à ação social.

\section{Sociedade, educação e (in)formação}

A extensão universitária ocupa lugar de destaque quando se discute o papel social das universidades. Ela é produtora de um conhecimento concretizado a partir das experiências em que os sujeitos se revezam nos papéis de autoria e de autonomia, e, quando são construídas numa relação dialógica, outros conhecimentos nascem. O conhecimento assim produzido é aquele que circula e que tem possibilidades de ser testado e de ter agregado a ele novos valores favorecendo assim a construção de um sujeito autônomo. Assim, discutir a extensão universitária como produtora de conhecimentos requer refletir sobre a inter-relação universidade e sociedade via educação e práxis (social e educativa).

Tomamos este caminho a partir de Castoriadis (1982, p. 95) quando comenta que a autonomia evidencia-se num processo concomitante com o desenvolvimento da práxis entendida como uma "[...] atividade consciente, só podendo existir na lucidez; mas ela é diferente da aplicação de um saber preliminar" que não pode ser reduzida a "esquema de fins e meios", tampouco a um saber técnico fragmentado o que imaginamos que aconteça nas ações de ensino e de pesquisa isolados. A extensão universitária agrega ensino e pesquisa na produção de conhecimentos sem ao menos excluir qualquer um dos elementos.

A autonomia dos sujeitos no dizer de Castoriadis (1882. p 129) não é a "[...] eliminação pura e simples do discurso do outro, e sim elaboração desse discurso, onde o outro não é material indiferente [...]" ela é uma empreitada da coletividade, do estar juntos fazendo e sendo história. Talvez esta seja a teoria da extensão - o abraçar, o tecer juntos uma ação que vislumbra a criação de alternativas educativas (e educacionais) significativamente diferente que proporciona o outro (ou os outros) ser um agente essencial do desenvolvimento de sua própria autonomia como prega Freire (1997).

Acreditando nessa proposição deste projeto fundado no diálogo Castoriadis (1982, p. 113) solicita: 
[...] poder participar diretamente de todas as decisões sociais que possam afetar minha existência ou o curso geral do mundo em que vivo. Não aceito que meu destino seja decidido, dia após dia, por pessoas cujos projetos me são hostis ou simplesmente desconhecidos e para quem não passamos eu e todos os outros, de números num plano ou peões sobre um tabuleiro de xadrez e que em ultima análise, minha vida e morte estejam nas mãos de pessoas que sei serem necessariamente cegas.

A partir deste autor, podemos questionar: em que sentido podemos dizer que a extensão universitária favorece a autonomia dos sujeitos? Se pensarmos como Castoriadis e Freire veremos que a questão da autonomia tal qual a do conhecimento é complexa; pois para o nosso estar no mundo eles são essenciais e estão sempre em movimento espiral esférico conjugado tanto no plano individual quanto no coletivo, pois o sujeito não existe isolado em si. Ele é induzido pelo mundo e pelos outros e nesse processo constrói os dispositivos necessários à sua inserção no mundo. Conseqüentemente, um sujeito autônomo assume, segundo Córdova (2004, p. 18), "[...] suas pulsões, seu desejo (Eros e Tanatos), sendo capaz de trazê-los à consciência, à expressão, à existência. Um sujeito autônomo é aquele capaz de reconhecer a sua "verdade" e os seus "desejos", mas não se deixa levar por eles.

Assim concebido, a autonomia e autoria do sujeito é uma questão individual e coletiva que implica pensar sobre que projeto de sociedade almejamos. Vimos que o biólogo chileno Humberto Maturana (2001) ao refletir sobre formação profissional questiona o papel da educação frente à realidade chilena e traz as seguintes perguntas: a educação chilena serve ao Chile e à sua juventude? E, remete a outros questionamentos: Que país queremos? Que educação queremos? Para que queremos educação? Que Universidade queremos? O biólogo responde a essas questões a partir de suas experiências quando estudantes e salienta que nesse período era evidente um projeto de responsabilidade social, no qual havia a preocupação com o bem-estar das pessoas.

Atualmente, diferente do que viveu Maturana, no Chile, percebe-se a configuração de um dilema entre um projeto individual voltado para a exigência do mercado profissional, competitivo. Neste século XXI, uma das questões que emerge para a redefinição da atuação da Universidade é o paradigma da formação profissional, tão privilegiado ao longo da sua história, mas que entra em xeque frente aos crescentes problemas sociais que sinalizam a emergência de seres autônomos, críticos, criativos, cooperativos, solidários e, sobretudo, dispostos e abertos a mudanças, a incertezas.

Uma possível crítica a esta formação profissional universitária, para o século XXI, poderia ser pautada no modelo de ciência moderna, sustentada na fragmentação e na especialização do saber, modelo este que repercute 
na construção de um conhecimento descontextualizado, hierarquizado e sem um diálogo com a realidade. Há neste modelo científico um domínio do knowhow técnico sobre o know-how ético; este seria necessário para aproximar a universidade dos interesses sociais, mesmo porque o paradigma que dominou o mundo ocidental da racionalização, da separação, da fragmentação, da especialização entra em crise e desafia as instituições produtoras de saberes a rever suas funções num mundo permeado pelas crises de percepção e de valores.

Nesta direção analítica, Santos (1996, p. 225 - grifo do autor), quando avalia as crises da universidade moderna (hegemonia, legitimidade e institucionalidade), propõe outro modelo de atuação desta instituição com a seguinte tese: "A "abertura ao outro" é o sentido profundo da democratização da universidade, uma democratização que vai muito além da democratização do acesso à universidade e da permanência nesta."

Morin (2002b) corrobora a tese de Santos ao abordar a reforma do pensamento, sugerindo que precisamos desenvolver um pensamento com a capacidade de ligar e solidarizar os conhecimentos que foram separados pelo paradigma do pensamento científico moderno, procurando integrar o local e o específico em sua totalidade e em seu contexto. Esta religação de saberes que se encontram dispersos poderá constituir-se no alicerce para a sustentação da responsabilidade e da cidadania dentro e fora da Universidade.

Fazendo uma conexão entre estes pensadores, vemos que o compromisso da educação universitária não poderá se prender somente a uma formação meramente instrumental, especializada, mas deverá aproximar-se da sociedade formando cientistas comprometidos com ela, sobretudo, com aqueles setores mais marginalizados da população. Albert Einstein (1981, p.29), o pai da teoria da relatividade, nos ajuda a refletir sobre a perspectiva da formação que estamos a pensar; assim diz o físico em sua obra Como Vejo o Mundo:

Não basta ensinar ao homem uma especialidade. Porque se tornará assim uma máquina utilizável, mas não uma personalidade. É necessário que adquira um sentimento, um senso prático daquilo que vale a pena ser empreendido, daquilo que é belo, do que é moralmente correto.

Numa analise do contexto de crises das Universidades brasileiras, Chauí (2001, p. 10) nos reafirma a necessidade de mudança do sentido da formação, hoje então, considerado no âmbito utilitário, operacional. Ao pensar a Universidade pública como investimento social e político, afirma:

há formação quando há obra de pensamento e que há obra de pensamento quando o presente é aprendido como aquilo que exige de nós o trabalho de interrogação, da reflexão e da crítica [...]. 
Por sua vez, Arendt (1993), ao discutir a condição humana, nos indica como elementos fundamentais: a palavra e a ação, aspectos defendidos por Freire (1987) na práxis educativa. Ela nos ensina que é através das palavras e de nossos atos que poderemos nos inserir no mundo e nos dar a oportunidade de um segundo nascimento. Este ocorre quando nos tornamos atores e agentes de nossos atos e, paralelamente, assumimos a autoria das palavras. Nesta perspectiva, a ação assume proeminência, mediante "a palavra falada na qual o autor se identifica. Não seria o espaço da extensão o campo de experimentação do diálogo, da ação?

Nessa discussão, a Comissão Permanente de Avaliação da Extensão Universitária, no documento Institucionalização da Extensão nas Universidades Públicas Brasileiras: estudo comparativo 1993/2004, mostra que $80,37 \%$ das universidades públicas definem essa relação como de alta prioridade. Diante das mais diversas possibilidades de confirmar esse diagnóstico; anunciamos que no Brasil, a partir da década de 1980, no contexto da abertura política, as discussões no mundo acadêmico centravam-se no resgate dos ideais democráticos e de uma sociedade mais justa. Passa a se discutir e a demandar das universidades o seu compromisso com os setores populares da nossa sociedade. Fato confirmado nos trabalhos de Azambuja (1997), Castro (2004), e Toscano (2006) que analisam propostas de atividades extensionistas. Uma análise dos aspectos conjunturais é de fundamental importância para orientar nosso pensamento. Assim no dizer de Castro (2004, p. 2):

Dentre as três funções da universidade, ensino, pesquisa e extensão, a última é a mais nova e a que carece de maiores investigações. A maioria dos trabalhos realizados enfoca o processo de construção histórica da extensão e sua inserção dentro da Universidade como uma terceira função. Porém, poucos são aqueles que investigam a prática dos projetos, seu dia a dia, sua influência no processo de formação dos discentes e sua contribuição para a consolidação de um campo de conhecimento específico e das conseqüências dessas práticas acadêmicas.

Dessa forma, as universidades vem delegando à extensão universitária o compromisso - e o comprometimento - pelo exercício da sua função social. Essa atitude é vista como um processo de democratização, difusão e produção de um conhecimento que é produzido no interior das instituições de educação superior. Diante desse cenário a extensão universitária, no Brasil, configurou-se como uma atividade que se reconstrói de maneira dinâmica e complexa.

Em suma, o propósito de empreender uma discussão sobre a democratização do conhecimento, via extensão universitária nos remete aos estudos de Freire $(1987,1999,2003)$, Morin $(1996,2002,2002 b, 2004)$ e Santos $(1996,2004,2004 b, 2005)$ que apontam para a possibilidade de um conhecimento-emancipação. 
Segundo Santos (2005), existe uma crise na ciência moderna provocada pelo desequilíbrio entre o conhecimento regulação e emancipação. Para este autor, o conhecimento regulação traz consigo as idéias do desenvolvimento da técnica e da ciência enquanto produtora de saber para o mercado, saber quase sempre descontextualizado, mas que é adequado às necessidades de quem o ordena (o mercado); já o conhecimento emancipação é aquele que favorece o pensar nas conseqüências de seus atos, isto é a relação entre sujeito-objeto e centra-se na reciprocidade onde a solidariedade e a participação estão presentes.

É na extensão universitária que vislumbramos que o conhecimento emancipador inter-relaciona-se com o regulador. Isso porque ela tem possibilidades de se concretizar como uma prática acadêmica que promove práticas integradas entre as várias áreas do conhecimento. Pode favorecer a aproximação de diferentes sujeitos permitindo, assim, a multidisciplinaridade e o desenvolvimento de uma consciência cidadã.

Esses exemplos podem ser no processo de (re)organização curricular quando Universidades brasileiras tendo em vista a idéia de flexibilização curricular implementaram uma concepção de extensão universitária em que o diálogo universidade e sociedade passam a ser visto como de "mão dupla", pois envolve docentes, discentes e comunidade.

Exemplos são dados através de reestruturações realizadas pela Universidade Federal da Bahia (UFBA) quando lança o programa de Atividade Curricular em Comunidade (ACC) em 2001.1, como atividade complementar optativa para todos os seus cursos de graduação; a Universidade Estadual de Campinas (Unicamp) criou, em 2001, as Atividades Multidiscipinares para que os estudantes possam atuar extramuros da Universidade; a Universidade Federal de São Carlos (UFScar), seguindo a experiência do Programa de Atividade Curricular em Comunidade (ACC) da Universidade Federal da Bahia (UFBA), criou a Atividade Curricular de Integração Ensino-Pesquisa-Extensão (ACIEPE), correspondendo a uma disciplina de 60 horas e 4 créditos. Envolve alunos e professores de diferentes cursos, os quais poderão construir conhecimento dialogando com a realidade e a Universidade Federal da Paraíba (UFPB), trouxe a idéia do Bloco de Componentes Curriculares Flexíveis (BCCF) que foi incluído a partir de 2003 nos cursos de graduação dessa instituição. A orientação é que o BCCF se realize em horários diferentes dos praticados nas disciplinas, podendo ocorrer no período letivo, ou no período de férias dos estudantes.

No nosso entendimento, estas experiências favorecem a eleição do conhecimento que Santos (2004, p. 41) definiu como sendo pluriversitário que para nós é um conhecimento transdisciplinar porque "[...] obriga a um diálogo ou confronto com outros tipos de conhecimento, o que o torna internamente mais heterogêneo e mais adequado a ser produzido em sistemas abertos menos perenes e de organização menos rígida e hierárquica". É onde vimos que sociedade e universidade se relacionam. 
Identificamos nas leituras sobre estas propostas de ações extensionistas que a vivência e a ação na extensão universitária possibilitam leituras críticas, questionadoras, curiosas, autônomas e complexas, no sentido de tecer juntos os saberes sobre o homem na sua relação com a natureza e a sociedade, fazendo assim uma leitura contextual, ou seja, a práxis vivenciada através da ação de fortalecimento da autonomia e de autoridade.

Constatamos nasleituras sobre estas experiências extensionistas a emergência de compartilharmos os valores da conservação, da cooperação, da parceria ao exercitar nossas percepções e pensamentos sobre a vida e o mundo, fundamentais ao sentido da responsabilidade ética e solidária entre os humanos. Pois, segundo Santos (1996, p. 229):

A universidade deverá criar espaços de interacção com a comunidade envolvente, onde seja possível identificar eventuais actuações e definir prioridades. [...] deve dar atenção privilegiada [...] à aprendizagem concreta de outros saberes no processo de "extensão.

Chama-nos a atenção para não permanecermos acomodados e sim compreendermos que o sol nasce para todos e que sempre podemos começar algo novo, como pensa Arendt (2004). Não seria o grande desafio para os alunos, professores e participantes das comunidades lutarem por mudanças em suas vidas e no contexto que os cerca?

Partimos da compreensão de que a ação extensionista deve ser compreendida como um espaço de diálogo e não como, apenas, transmissora de conhecimentos. Nela o conhecimento emancipador inter-relaciona-se com o regulador. Isso porque ela tem possibilidades de se concretizar como uma prática acadêmica que promove práticas integradas entre as várias áreas do conhecimento. Pode favorecer a aproximação de diferentes sujeitos permitindo, assim, a multidisciplinaridade e o desenvolvimento de uma consciência cidadã; permitindo que os estudantes extensionistas, no seu processo de formação, sejam entendidos como sujeitos comprometidos com a mudança e capazes de se colocarem no mundo com uma postura mais ativa e crítica; envolvidos com a sociedade.

Nessa linha reflexiva, na extensão universitária permite-se o diálogo entre os conhecimentos acadêmicos e culturais, possibilitando a democratização do conhecimento e a efetiva participação da comunidade em suas atividades, bem como a produção de novos conhecimentos a partir do confronto com a realidade. É um espaço em que a teoria e prática perdem as fronteiras, sem tornarem-se excludentes. 


\section{(In) conclusões}

Se a extensão tem se apresentado como uma terceira função na universidade este é um discurso que não podemos mais legitimar. Precisamos partir para ações efetivas em busca da valorização e compreensão da extensão universitária como um dos caminhos da universidade legitimar-se no espaço em que ela está inserida, dar vez, abrir espaço para o discurso, para a palavra, para a ação.

Dessa forma, vislumbramos que na extensão universitária a produção de conhecimentos é fruto de interações sócio-cultural que evidenciam processos cognitivos válidos que se apóiam numa conjunção de saberes/conhecimentos provisórios, mas não fragmentados ou descontextualizados. Para tanto, a extensão universitária entendida como um processo educativo favorece a autonomia dos sujeitos numa relação interna e intensa visando à superação de uma teoria de concretude e finitude dos processos históricos humano que acontecem numa relação de diálogo que conduz a autonomia.

Mesmo considerando o espaço acadêmico como lócus privilegiado para o exercício da criticidade elas podem ser definidas "[...] por seu caráter de instituição oficial, fundada ou reconhecida por uma autoridade religiosa ou política" (Verger; Charle, 1996, p. 43-44). Se essas limitações são comuns e presentes nas bibliografias referentes à História das Universidades, é com indignação que apreciamos, ainda hoje, esse mesmo quadro.

Por fim, a análise que se faz hoje do conhecimento produzido nas universidades vem demonstrando que, ela tem exercido o papel de produtora de conhecimento. A esse respeito há de se destacar que as universidades vêm produzindo cientificamente seu itinerário: sala de aula - produto mercado. O que, no nosso entendimento a descaracteriza enquanto produtora e socializadora do saber; e que agora se vê comprometida com a lógica do mercado que determina retornos possíveis e condizentes com os interesses do capital.

Em virtude de elevados investimentos em áreas do conhecimento consideradas nobres as universidades vêm procurando redefinir seu papel para poder enfrentar as tensões da contemporaneidade, pois antes de inserirse num mundo global ela necessita tornar-se complementar. A noção de complementaridade se faz presente na idéia de religação e significação dos saberes nela produzido.

Sem perder de vista a historicidade do processo instituinte e das relações que se estabelecem os sujeitos envolvidos nas ações de extensões (discentes, docentes e comunidade) esta interação proporciona uma multiplicidade de aspectos advindos, tanto do saber científico, como do saber popular (e comunitário), expressos em diferentes linguagens desprezadas ou ausentes muitas vezes nos espaços das salas de aulas. 
Ao ter a comunidade como "espaço de aprendizagem" pode-se perceber a natureza das múltiplas referências que circunda esse espaço plural. Por isso entendemos que estudar o discurso é ir além das interpretações das falas. Assim nas atividades de extensão o processo de ensino e aprendizagem é interativo e comunicativo e o conhecimento é (re) elaborado através de práticas sociais que envolvem significantes e significados

A comunidade enquanto espaço construtor de aprendizagens é onde se propaga a comunicação. Nessa perspectiva, acreditamos na possibilidade de concebermos relações de produção de conhecimento "olhando" por/ nesse espaço que pode estar carregado desubjetividades que não se materializam, não ganha forma, pois é fruto de uma incorporação que acontece idiossicraticamente, ou seja, os diálogos que se estabelecem no "universo" constituem na subjetividade dos indivíduos

É preciso, portanto, não perder de vista que a práxis transformadora (re) elaborada nos espaços de aprendizagens tende a ser praticada porque tem a capacidade de mobilização. Por isso, pensamos, não ser possível, o divórcio entre teoria e prática. Uma vez que, ou em qualquer outro espaço, fundamenta e orienta práticas, não tecnicamente, mas consciente do seu poder de luta política e social expressa no comprometimento/compromisso com o exercício da cidadania.

Em suma, é importante frisar que não existe qualquer possibilidade de transcendência quando a ação está desvinculada do contexto. É necessário, pois, estar atentos ao "aprender a ensinar" e ao "aprender a aprender" já que só se aprende efetivamente quando construímos estratégias próprias de ação do/no real, ou seja, quando o subjetivo se objetiva. Em síntese, a reorganização das idéias se atualiza a partir do momento em que refletimos individualmente e coletivamente, esse talvez seja o caminho que vem seguindo a extensão universitária.

Estabelecer uma conexão entre sociedade, educação e práxis via extensão universitária e democratização de conhecimentos requer (re)pensar e tensionar os caminhos que embasam o processo formativo da/na vida acadêmica. Nesse labirinto de estrelas é possível compreender os espaços formais de educação enquanto um aparato polissêmico e devorador voraz das nossas experiências resultantes de trocas afetivas e intelectuais, mas que (re)definem um lugar responsavel pela produção de conhecimento. Assim, neste emaranhado, bifurcado e hologramático campo o que vimos (e continuamos a ver) é a legitimação de um abismo entre os saberes sociais e o científico.

Não foi nossa intenção definir ou veicular a extensão universitária como redentora e menosprezar outras alternativas de ensino e pesquisa que possam (e promovam) o dialogo entre os conhecimentos, apenas almejamos que o principio educativo seja um espaço de negociação, de sentidos e conflitos entre distintas finalidades mesmo acreditando que nas ações extensionistas 
há um tencionamento de uma pratica de educação em que o processo de (re) construção de conhecimento se dá pelo estreitamento das fronteiras entre teoria e prática e converte-se em uma categoria (epistemológica) multirreferencial capaz de agrupar uma ampla variedade de práticas educacionais (e educativas) desenvolvidas nas comunidades e nos espaços das salas de aula podendo ser um exemplo significativo do interesse em contribuir para melhorar os processos de ensino e de aprendizagem e ampliar as relações e repertórios disponíveis aos dialogo com outras formas de saberes e conhecimentos tidos como provisórios, inacabados.

\section{Referencias}

- $\quad$ Einstein, A. (1981) Como vejo o mundo. Trad. H. P de Andrade. Rio de Janeiro: Nova Fronteira.

- $\quad$ Arendt, H. (1993) Vida do espírito - o pensar, o querer, o julgar. Trad. Antonio Abranches. 2 ed. Rio de Janeiro: Relume Dumará.

- $\quad$ (2004) Condição humana. Rio de Janeiro: Forense Universitária.

- $\quad$ Azambuja, E. (1997) A extensão universitária na UNIJUí. In: Cadernos da Avaliação Institucional. ljuí: UNIJUÍ, nº 12, p. 43-45.

- Brasil, Ministério da Educação. Secretaria de Educação Superior. Fórum de PróReitores das Universidades Públicas Brasileiras (FORPROEX). Plano nacional de extensão universitária, 2000 - 2001. Disponível em: <http://www.renex.org/arquivos/ pne/planonacionaldeextensão.doc> Acesso em: 20 nov. 2005.

- Buarque, C. (1994) A aventura na universidade. São Paulo: Ed. UNESP; Rio de Janeiro: Paz e Terra.

- $\quad$ Castoriadis, C. (1982) A instituição imaginária da sociedade. Trad. Guy Reynaud. Rio de Janeiro: Paz e Terra.

- Castro, L. M. C. A avaliação da extensão universitária na UERJ: resultados e desafios. In. Anais do $2^{\circ}$ Congresso Brasileiro de Extensão Universitária. Belo Horizonte -12 a 15 de setembro de 2004.

- Chauí, M. (2001) Escritos sobre a universidade. São Paulo: Ed. UNESP.

- Córdova, R. de A. (2004) Instituição, educação e autonomia: na obra de Cornelius Castoriadis. Brasília: Plano Editora.

- $\quad$ Cunha, L. S. (2001) O mal estar da universidade: a tensão nos anos 90. Niterói, $255 \mathrm{f}$. Tese (Doutorado em Educação). Universidade Federal Fluminense.

- $\quad$ Fagundes, J. (1985) Universidade e compromisso social: extensão, limites e perspectivas. Campinas. 170p. Universidade de Campinas (Tese de doutorado em educação).

- $\quad$ Fórum de Pró-reitores de Extensão das Universidades Publicas Brasileira (FORPROEX). GT - Indissociabilidade Ensino-Pesquisa-Extensão e Flexibilização Curricular. Disponível em: <http://www.renex.org.br/noticias.php?NotlD=143>. Acesso em: 06 abril de 2008.

- $\quad$ Freire, P. (2006) Extensão ou comunicação? 13 ed. Rio de Janeiro: Paz e Terra

- $\quad$ (1983) Educação como prática de liberdade. 18 ed. Rio de Janeiro: Paz e Terra.

- $\quad$ (1987) Pedagogia do oprimido. 17 ed. Rio de Janeiro: Paz e Terra. (1993) Educação e mudança. 19 ed. São Paulo: Paz e Terra. (Coleção Educação e comunicação, v. 1). 
ـ (1999) Pedagogia da autonomia: saberes necessários à prática educativa. 13 ed. Rio de Janeiro (Coleção leitura). da Nossa Época, v. 23).

(2003) Política e educação. 7 ed. São Paulo: Cortez. (Coleção Questões

- Jezine, E. M. (2006) A crise da universidade e o compromisso social da extensão universitária. João Pessoa: Editora da UFPB.

- Marx, K.; Engels, F. (2004) Manifesto do partido comunista. São Paulo: Martin Claret.

- Maturana, H. (2001) Emoções e linguagem na educação e na política. Belo Horizonte: Ed. UFMG.

- Morin, E. (1996) Ciência com consciência. Rio de Janeiro: Bertrand Brasil.

- . (2000) Os sete saberes necessários à educação do futuro. 2 ed. Trad. Catarina E. F. da Silva e Jeanne Sawaya. São Paulo: Cortez; Brasília: UNESCO.

Ed. Sulinas. (2002a) O método 3: o conhecimento do conhecimento. Porto Alegre: (2002b) A religação dos saberes: o desafio do século XXI. 2. ed. Rio de Janeiro: Bertrand Brasil.

. (2004a) A cabeça bem feita: repensar a reforma, reformar o pensamento. 3 ed. Rio de Janeiro: Bertrand Brasil.

- Nogueira, M. D. P. (Org.) (2000) Extensão universitária: diretrizes conceituais e políticas. Documentos básicos do Fórum Nacional de Pró-Reitores de Extensão das Universidades Públicas Brasileiras 1987 - 2000. Belo Horizonte: UFMG/PROEX; FORPROEX.

UFMG. (2005) Políticas de extensão universitária brasileira. Belo Horizonte: Ed.

- Paiva, V. P. (1974) Extensión universitária em Brasil. San José: Nueva Sociedad.

- Santos, B. de S. A Universidade no século XXI: para uma reforma democrática e emancipatória da universidade In. Santos, Boaventura de Sousa; Almeida Filho, Naomar. A universidade no século XXI: para uma universidade nova. Coimbra: Edições Almedina, 2008. p. $5-106$.

(2006) A gramática do tempo: por uma nova cultura política. São Paulo: Cortez. (Coleção para um novo senso comum; v. 4).

(2005) Para um novo senso comum: a ciência, o direito e a política na transição paradigmática. 5 ed. São Paulo: Cortez. (v.1: A crítica da Razão indolente: contra o desperdício da experiência).

. (2004a) A universidade no século XXI: para uma reforma democrática e emancipatória da universidade. São Paulo: Cortez. (Coleção Questões da Nossa Época, v. 120).

- ㄴ. (2004b) Um discurso sobre as ciências. 2. ed. São Paulo: Cortez.

- $\quad$ (Org.) (2004c) Conhecimento prudente para uma vida decente: um discurso sobre as ciências revisitado. São Paulo: Cortez.

Paulo: Cortez. (2000) Pela mão de Alice: o social na pós-modernidade. 7. ed. São

- $\quad$ Serpa. L. F. P. (1987) Sobre a práxis pedagógica. Educação em Debate. Fortaleza, 14 (2): jul/dez.

- Shiva, V. (2003) Monoculturas da mente: biodiversidade e biotecnologia. São Paulo: Editora Gaia.

- Sousa, A. L. L. (2000) A história da extensão universitária. Campinas, SP: Alínea.

- Toscano, G. da S. (2006) Extensão universitária e formação cidadã: a UFRN e a UFBA em ação. 2006. 276f. Tese (Doutorado em Ciências Sociais) - Programa de Pós-Graduação 
em Ciências Sociais, Centro de Ciências Humanas, Letras e Artes, Universidade Federal do Rio Grande do Norte, Natal/RN.

- Vázquez, A. S. (2007) Filosofia da práxis. 1 ed. Buenos Aires: CLACSO; São Paulo: Expressão Popular.

- Verger, J.; Charle, C. (1996) História das universidades. São Paulo: Ed. da Universidade Estadual Paulista. (Universitas). 